\title{
Is hypertension associated with a greater increase in creatine kinase activity following cycling exercise? A case study
}

\author{
Debora Henriques' ${ }^{1}$, Ester Tebaldi ${ }^{1}$, Tamires Coelho ${ }^{1}$, Alvaro Dutra ${ }^{2}$, Rafael Pereira ${ }^{5}$, Alexander J Koch ${ }^{3}$, \\ and Marco Machado, ${ }^{1,4}$ \\ 'Laboratory of Physiology and Biokinetics, Universidade Iguaçu at Itaperuna, Itaperuna, RJ, Brazil \\ ${ }^{2}$ Centrolab, Itaperuna, $R J$, Brazil \\ ${ }^{3}$ Exercise Physiology Laboratory, Lenoir-Rhyne University, Hickory, NC USA \\ ${ }^{4}$ Laboratory of Human Movement Studies, Universitary Fundation of Itaperuna, Itaperuna, RJ, Brazil \\ ${ }^{5}$ Integrative Physiology Research Center, Department of Biological Sciences, State University of Southwest Bahia (UESB), Jequie 45210-506, Bahia, Brazil
}

\begin{abstract}
We describe discrepant behavior of serum creatine kinase (CK) activity during and after cycling in a hypertensive athlete when compared to the healthy athletes from the same team of endurance cyclists. Heart Rate (HR), Blood Pressure (BP), Perceived Exertion (PE) and serum CK activity were evaluated before, during and after $150 \mathrm{~km}$ indoor cycling. The results showed that there were no differences between the hypertensive athlete and the healthy athletes in time trial (186.3 $\mathrm{min}$ vs. $179.1 \pm 14.9 \mathrm{~min}), \mathrm{HR}(159.3 \pm 11.4 \mathrm{bpm}$ vs. $169.5 \pm 7.8 \mathrm{bpm}$ respectively) and $\mathrm{PE}(6.3 \pm 1.5$ vs. $6.3 \pm$ 1.3). Systolic BP was higher in hypertensive athlete before, during and after the exercise. Serum CK activity was higher $(+47 \%)$ at baseline and exhibited a higher increase $(>+200 \%)$ after exercise. Our finding shed light on a hypothesis regarding the interindividual variability of serum $\mathrm{CK}$ activity and its possible interaction with hypertension.

Key words: blood pressure, creatine kinase, muscle damage, endurance

$$
\text { Arterial Hypertens. 2018, vol. 22, no. 2, pages: 104-106 }
$$$$
\text { DOI: } 10.5603 / A H . a 2018.0004
$$

\section{Introduction}

Creatine Kinase (CK) plays critical role in metabolism and has also been positively associated with resting blood pressure $[1,2]$. Brewster et al. [2] showed association between basal serum CK and BP in 1444 citizens (503 self-defined White Europeans, 292 South Asians, 580 blacks, and 69 of other ethnicity), aged 34 to 60 years. They hypothesized that relatively high tissue CK activity and ATP buffer capacity enhance cardiovascular contractility and the ability to retain salt and thereby increase the risk of hypertension.

Address for correspondence: Dr. Marco Machado Assistant Professor, Laboratory of Human Movement Studies, Universitary Foundation of Itaperuna, Itaperuna, RJ, Brazil e-mail: marcomachado1@gmail.com

V M Copyright () 2018 Via Medica, ISSN 2449-6170

\section{Presentation of the case}

A team of semi-professional endurance cyclists came to our laboratory for assessment. From all athletes, W. F. C. (30 years old; 15 years as athlete; $140 \mathrm{~km}$ for week; $102.0 \mathrm{~kg} ; 175 \mathrm{~cm}$; which hitherto he thinks to be healthy, and was drug-naive including statins use) presented elevated resting blood pressure values, and as all other athletes he was informed about all the experimental procedures and signed an informed consent. The study was approved by the local Research Ethics Committee.

Subsequent blood pressure assessment and blood biochemical analysis confirmed the hypertension $(150 / 100 ; 150 / 110 ; 150 / 110 \mathrm{mmHg}$, three consecutive days in the morning), dyslipidemia (total cholesterol $235.0 \mathrm{mg} / \mathrm{dL}$; triglycerides $245.0 \mathrm{mg} / \mathrm{dL}$; HDL $56.0 \mathrm{mg} / \mathrm{dL}$; LDL $90.0 \mathrm{mg} / \mathrm{dL}$; Total Lipids $605 \mathrm{mg} / \mathrm{dL}$ ) and proteinuria $(>8.0 \mathrm{mg} / \mathrm{dL})$. Serum 


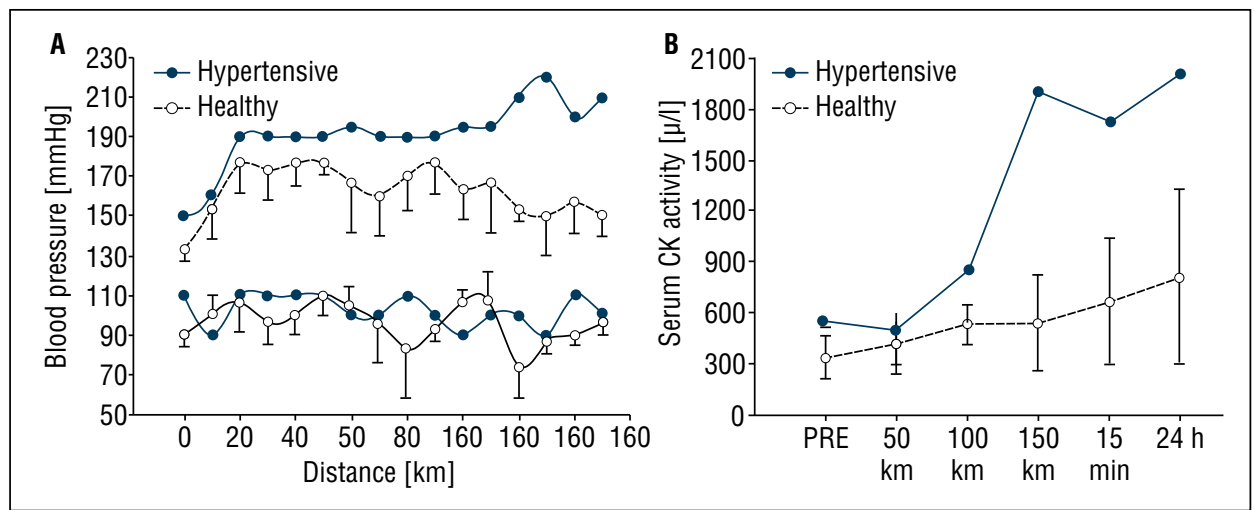

Figure 1. Blood pressure assessment before and during training session $(150 \mathrm{~km})(\mathbf{A})$, and Serum CK activity before, during and after exercise session (B)

CK activity was $500.0 \mathrm{U} / \mathrm{L}$, normal for athletes during season [3], but higher when compared to other team members $(340.7 \pm 124.1 \mathrm{U} / \mathrm{L})$.

During teamassessment thecyclistsperformed $150 \mathrm{~km}$ pedaling using their own bikes placed on cycling training rollers (Altmayer Sport, Mafra-SC, Brazil). Intensity was $75-90 \%$ of maximum heart rate (HR). HR, blood pressure (BP) and perceived exertion [4] were measured before, during (every $10 \mathrm{~km}$ ) and after training (15 and 30 minutes). Blood samples were collected before, every $50 \mathrm{~km}$, and after (15 min and 24h) the ride for serum CK activity assessment.

The changes in HR (hypertensive $=159.3 \pm 11.4$ bpm; healthy $=169.5 \pm 7.8 \mathrm{bpm}$ ) and perceived exertion (hypertensive $=6.3 \pm 1.5$; healthy $=6.3 \pm 1.3$ ) of the hypertensive subject during the $150 \mathrm{~km}$ trial was similar to the healthy subjects. Time to complete $150 \mathrm{~km}$ was also similar between hypertensive and healthy subjects, at $186.3 \mathrm{~min}$. vs. $179.1 \pm 14.9 \mathrm{~min}$., respectively.

As expected, the hypertensive athlete's systolic BP was higher before and during training session when compared with healthy athletes BP. In the healthy athletes a tendency towards decreasing SBP and DBP during the final $50 \mathrm{~km}$ as compared to the first $100 \mathrm{~km}$ was noted, though these blood pressure values were all higher than resting. The described trend was not evident in a hypertensive athlete.

As expected, serum CK activity increased after the training session in all athletes, however, a hypertensive athlete showed evidently higher CK values increases (> 200\%) when compared with healthy athletes (Fig. 1).

\section{Discussion}

Our results corroborate the previous findings of Brewster $[1,2]$, in that the hypertensive individuals are characterized by higher CK levels at rest. In addition, we observed that the hypertensive and dyslipidemic athlete showed greater increases in serum CK activity when compared with healthy athletes during and after training session. Despite the suggestion that hypertension may be related to the CK activity, we cannot say that the increase in BP during exercise is related to increased release of CK. We hypothesize that, unlike the resting condition, in which greater $\mathrm{CK}$ activity is postulated to play a causal role in the development of hypertension [1], it is possible that hypertension plays a causal role in the greater elevation of CK during and following activity. The rate of release of $\mathrm{CK}$ is related to the velocity of the lymph [5]. Hypertension is associated with increased filtration and formation of interstitial fluid, resulting in a greater lymph flow rate $[6,7]$. Thus we speculate that the hypertensive subject experienced an increased lymph flow rate, which led to a more rapid accumulation of CK in the bloodstream. Thus, CK activity and hypertension act to amplify each other, with higher CK activity at rest leading to hypertension and hypertension leading to elevated CK responses to exercise.

The obvious limitations of our study were that we observed only one hypertensive subject and, second, we did not measure lymph flow velocity. Thus our findings and its interpretations warrant further verification in larger-scale studies.

\section{Conclusions}

Our findings lead us to conclude that hypertension may be implicated in altered variability of serum CK activity at rest and during activity.

\section{References}

1. Brewster LM, Mairuhu G, Bindraban NR, et al. Creatine kinase activity is associated with blood pressure. Circulation. 2006; 114(19): 
2034-2039, doi: 10.1161/CIRCULATIONAHA.105.584490, indexed in Pubmed: 17075013.

2. Brewster LM, Stronks K, Zwinderman AH, et al. Creatine kinase and the correlates of blood pressure in a random population sample. Hypertension. 2008; 51(1): e4-e5, doi: 10.1161/HYPERTENSIONAHA.107.091835, indexed in Pubmed: 18071057.

3. Mougios V. Reference intervals for serum creatine kinase in athletes. Br J Sports Med. 2007; 41(10): 674-678, doi: 10.1136/ bjsm.2006.034041, indexed in Pubmed: 17526622.

4. Borg G. Borg's Perceived Exertion and Pain Scales. Human Kinetics, Champaign. 1998.
5. Sayers SP, Clarkson PM. Short-term immobilization after eccentric exercise. Part II: creatine kinase and myoglobin. Med Sci Sports Exerc. 2003; 35(5): 762-768, doi: 10.1249/01.MSS.0000064933.43824. ED, indexed in Pubmed: 12750585.

6. Valenzuela-Rendon J, Manning RD. Chronic lymph flow and transcapillary fluid flux during angiotensin II hypertension. Am J Physiol. 1990; 259(6 Pt 2): R1205-R1213, doi: 10.1152/ ajpregu.1990.259.6.R1205, indexed in Pubmed: 2260731.

7. Paulus BM, Ali S, Zia AA, et al. Causes and consequences of systemic venous hypertension. Am J Med Sci. 2008; 336(6): 489-497, doi: 10.1097/MAJ.0b013e318176abe9, indexed in Pubmed: 19092322. 